\title{
Tuberculoma of the orbit and lacrimal gland
}

\author{
ALY MORTADA \\ Department of Ophthalmology, Faculty of Medicine, Cairo University, Egypt
}

The three following cases of tuberculoma, one of the orbit and two of the lacrimal gland, are described because of their rarity (Offret, I939; Duke-Elder, I952).

\section{Case reports}

The three patients reported below were in good general condition, with no enlargement of the lymph glands, liver, or spleen. Apart from increased lymphocytes the blood count was normal. The urine was free from albumin and sugar. The blood pressure, pulse rate, and body temperature were normal. The faeces showed no parasitic ova. There was no abnormality of the chest, air passages, abdomen, skin, or bones. The blood Wassermann reaction was negative. There were no septic foci in the body. Skull $x$ rays showed no abnormality of the orbital bones. There was no history of trauma, and no signs of syphilis, sarcoidosis, or Mikulicz's disease. The tuberculin test was positive.

Case 1 , an obese woman aged 35 years, complained of gradual painless proptosis of the left eye of 6 months' duration.

The right eye and fundus were normal, and the visual acuity was $6 / 6$.

The left eye showed a forward proptosis of $20 \mathrm{~mm}$. (Hertel) with downwards limitation of ocular movements. The fundus was normal and the visual acuity was 6/9. A hard orbital mass was felt in the lower eyelid extending backwards below the eye into the orbit. When the mass was pressed backwards the globe was made to protrude forwards.

The tumour, which was removed through a lower fornix conjunctival incision, measured $2 \cdot 5 \times 1 \cdot 5 \times 1 \mathrm{~cm}$. and was pink, firm, and encapsulated. Histopathological examination showed a granulomatous structure with giant cells (Fig. I) which is characteristic of tuberculoma, but tubercular organisms were not seen.

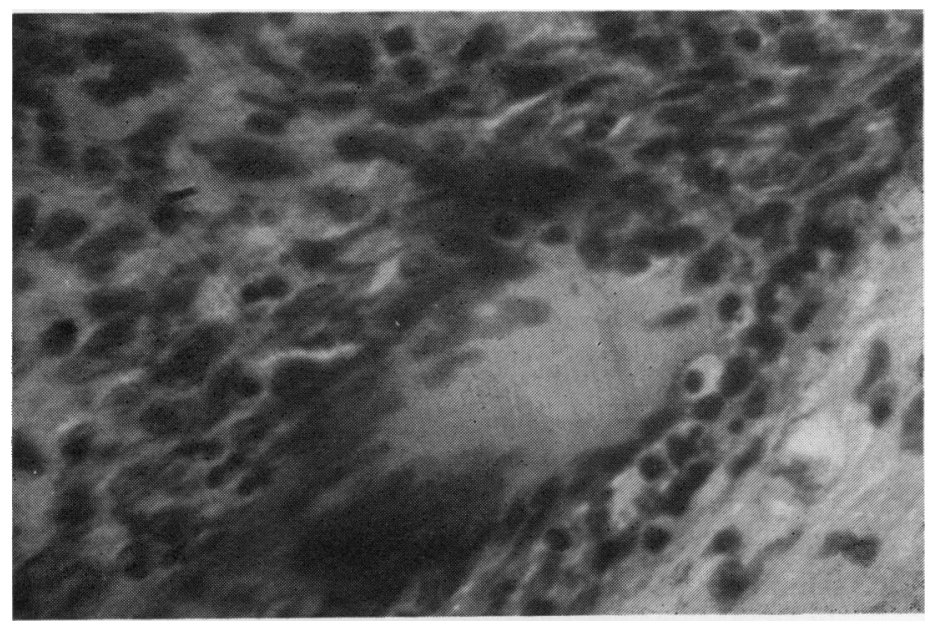

FIG. I Case I. Tuberculoma of orbit, section showing giant cell system. 
Case 2, a woman aged 40 years, complained of gradual painless proptosis of the right eye of 7 months' duration (Fig. 2).

The left eye was normal.

The right upper eyelid showed ptosis, the eye was pushed downwards and inwards with limitation of ocular movements up and out. The fundus was normal and the visual acuity 6/12. The proptosis measured $21 \mathrm{~mm}$. (Hertel), there was oedema of the right upper lid, and the palpebral and orbital parts of the right lacrimal gland were palpable. Both parts of the gland were excised.

Histopathological examination of the mass showed a tuberculoma of the lacrimal gland with typical giant cell systems (Fig. 3).

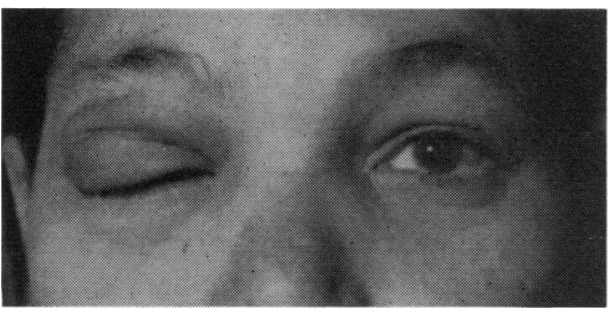

FIG. 2 Case 2. Right proptosis and ptosis due to tuberculoma of lacrimal gland of 7 months' duration in a woman aged 40 years

FI G. 3 Case 2. Tuberculoma of lacrimal gland, section showing giant cell system among acini of gland. $\times 120$

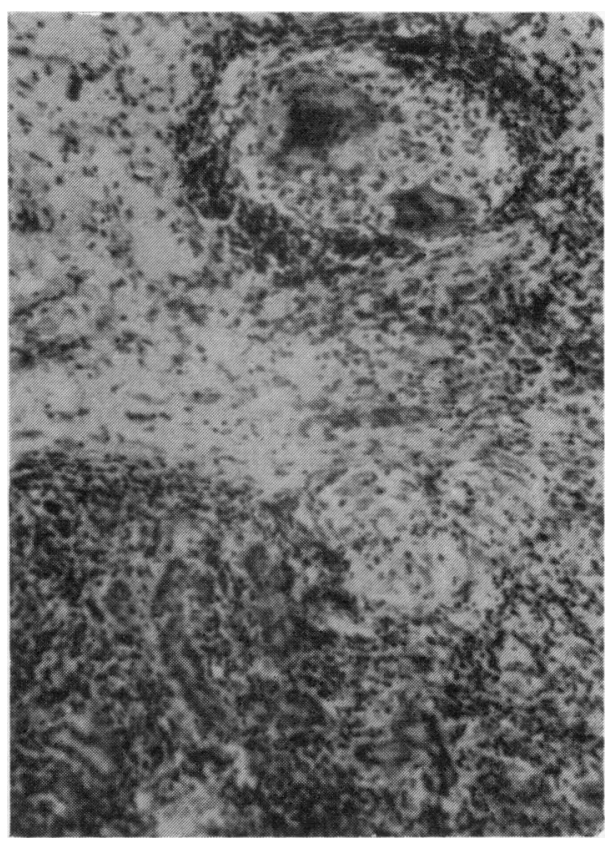

Case 3, a woman aged $3^{8}$ years, complained of gradual right proptosis of 5 months' duration (Fig. 4).

The left eye was normal with a visual acuity of $6 / 9$.

There was right ptosis, oedema of the right eyelids, and chemosis of the conjunctiva, with proptosis downwards measuring $2 \mathrm{I} \mathrm{mm}$. (Hertel). There was limitation of ocular movements upwards. The right fundus showed engorged retinal vessels and a visual acuity of 6/18. The palpebral and orbital parts of the right lacrimal gland were enlarged and were excised.

Histopathological examination showed a tuberculoma of the lacrimal gland with typical giant cell systems (Fig. 5). Sections were negative for tubercular organisms.

In these three patients, the excision of the orbital mass was followed by a course of intramuscular streptomycin injections. There was no recurrence of the orbital mass or proptosis during a 5-year follow-up.

\section{Discussion}

Tuberculosis of the lacrimal gland was first described by Abadie (I88I) and since then many reports have appeared in the literature (Motto and Rowen, I929; Wilson, 1937; Heath, 1947). The infection is usually haematogenous and the acute miliary form is rare. The localized isolated form seen in these three cases is more important clinically, and often occurs in persons with healed lesion of the lungs, lymph glands, or bones. The isolated form is usually of the sclerotic and rarely of the caseous type. 


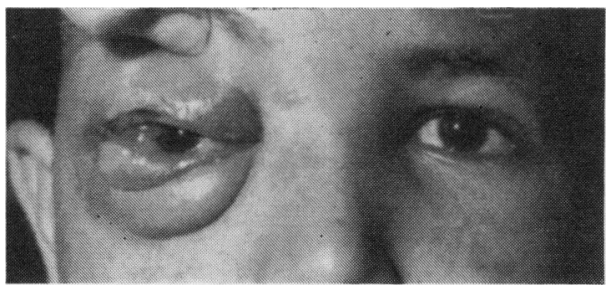

FIG. 4 Case 3. Right proptosis, ptosis, and oedema of lids due to tuberculoma of lacrimal gland of 5 months' duration in a woman aged 38 years

Fig. 5 Case 3. Tuberouloma of lacrimal gland, showing giant cell system among acini of gland. $\quad \times 120$

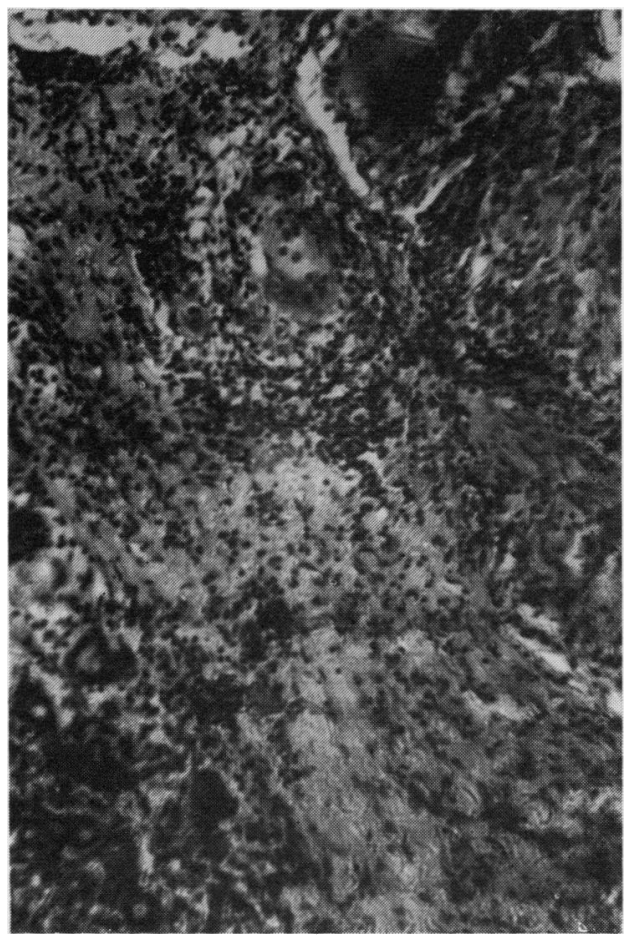

Cases of orbital tuberculoma may present as unilateral proptosis, as a unilateral partial or complete superior orbital fissure syndrome, or as an orbital apex syndrome of uncertain origin (Mortada, 196r). The diagnosis can be confirmed only by orbital exploration, biopsy, and histopathological examination.

Tuberculoma of the orbit and lacrimal gland usually affects females of 35 to 50 years of age as in these three cases. Excision of the lesion followed by streptomycin injections gives complete cure with no recurrence of the proptosis or the orbital mass.

\section{Summary}

(1) Three rare cases of tuberculoma, one of the orbit and two of the lacrimal gland, are described.

(2) The three cases occurred in women aged 35, 38, and 40 years.

(3) Diagnosis was by excision of the tumour and histopathological examination.

(4) Apart from a positive Mantoux test, there were no active tuberculous lesions in the lungs, lymph glands, bones, or skin. There may have been a healed focus in the lungs.

(5) A 5-year follow-up did not show any recurrence of the orbital mass or the proptosis.

\section{References}

ABAdie, C. (188I) Arch. Ophtal., r, 432

DUKE-ELDER, S. (1952) “Text-book of Ophthalmology", vol. 5, p. 5459. Kimpton, London

HEATH, P. (1947) Trans. Amer. ophthal. Soc., 45, 269

MORTADA, A. (I961) Brit. 7. Ophthal., 45, 662

мотто, м. P., and RoWen, E. H. (1929) Amer. 7. Ophthal., 12, 8 1 8

OFFret, G. (1939) "Les myosites orbitaires". Doin, Paris

wilson, R. P. (I937) I I th Ann. Rep. mem. ophthal. Lab., Giza, 1936, Ix, 72 